ToSEE - Tourism in Southern and Eastern Europe, Vol. 6, pp. 559-572, 2021.

I. Pavlić, A. Portolan, B. Puh: IMAGE FORMATION IN RURAL TOURISM DESTINATION

\title{
IMAGE FORMATION IN RURAL TOURISM DESTINATION
}

\author{
Ivana Pavlić \\ Ana Portolan \\ Barbara Puh
}

https://doi.org//10.20867/tosee.06.38

\begin{abstract}
Purpose - Tourism can be an efficient factor of quality and sustainable development especially in the countryside. Nowadays many rural communities are facing agriculture decline and tourism can enable a new concept of economic development. Rural tourism is multifaceted since it can consolidate agriculture, forestry, farming, heritage with numerous and various tourism activities far away from urban center and mass tourism. Forming positive tourism image in such destination is essential. The focal purpose of this paper is to empirically test a concept of rural tourism destination image formation which did not fully commercialize their potential as a tourism destination and to define the relationship between different parameters and the image of rural tourism destination.

Methodology - For the purpose of identification the relationship amidst different parameters and rural tourism destination image empirical research has been conducted applying accessible deliberate sample of tourists (600) who had visited rural areas near famous world tourism destination - Dubrovnik, Croatia in a period June 2017 - January 2018. 534 questionnaires were found to be fulfilled correctly and were used in further analysis. Data were analyzed in three steps. First, to detect the sub dimensions of affective and cognitive determinants of image exploratory factor analysis was enforced. Secondly, to test validity of the dimension of the different image components, confirmatory factor analysis was used. Thirdly, structural equation modeling was used to examine which dimension has important influence on the rural tourism destination overall. Findings - The findings suggest several differences among various analyzed image dimensions. The affective dimension of the image has an important aspect in image formation and has significant influence on the rural tourism destination overall image.

Contribution - The results of this paper have provided useful strategic direction for the rural tourism destination in order to improve their competitiveness. To upgrade the current image into the marketing strategy, affective image dimension of the rural tourism destination such as experience should be presented in the further marketing communication of the regional and national tourist boards.
\end{abstract}

Keywords: image formatting, rural tourism destination, Dubrovnik Neretva County.

\section{INTRODUCTION}

In today's world tourism is considered to be an important promoter of development and growth. Bearing in mind the fact that many rural areas are facing the problems of agricultural decline and depopulation tourism can be seen as one of the main concepts for redevelopment of these spaces. In order to do that, creating appropriate image is important due to the better positioning compared to direct and indirect competitors (Leković et al. 2020). Considering the fact that the number of tourism destinations constantly increases creating a unique image has become an imperative and most 
ToSEE - Tourism in Southern and Eastern Europe, Vol. 6, pp. 559-572, 2021.

I. Pavlić, A. Portolan, B. Puh: IMAGE FORMATION IN RURAL TOURISM DESTINATION

important factor to survive in a competitive, complex and fast growing tourism market. Regardless of the growth of rural tourism destinations all around world, limited research has been made in this field especially in the part where rural tourism is related to destination image.

According Zhou $(2014,227)$ image of rural destination can be examined "from the destination identity perspective which can be divided into two streams of research social and cultural representation of the destination and rural destination branding - and from the perspectives of tourist behavior and the market segmentation of rural tourism". The tourist behavior and their attitudes are the main focus of this research.

The aim of this paper is to emphasize the importance of researching rural tourism destination image from the tourists' perspective. In the first part of the paper, literature review of rural tourism and image has been analyzed. Furthermore, data and methodology, including research area, sampling, questionnaire design and analytical procedure was presented following the results and discussion part. The paper finishes which conclusion and references.

This paper's objective is two folded. First, it explores cognitive and affective elements of rural tourism destination image and secondly it defines the coherency among cognitive and affective elements and overall rural tourism destination image from tourists' point of view.

\section{LITERATURE REVIEW}

\subsection{Rural tourism}

Rural tourism, as a base for preserving cultural and historical identity, customs and traditions of rural areas, has recently emerged as a distance from the mass, standardized and unsustainable tourism that has arisen as a result of industrialization and urbanization. Industrialization has led to the relocation of the population from rural areas to cities which have consequently resulted with depopulation and decay of rural areas, and intensive urbanization has created an increased tourism demand for quiet rural areas. The potential of rural tourism is mirrored in year-round business, reducing the seasonality of coastal destinations and relieving the urban space, which before the COVID-19 pandemic were overloaded with tourism. It also allows consumers to return to the natural environment and relief from pressure and stress of everyday life in urban areas (Ružić, 2009) and offer the opportunity to re-engage with a simpler, more peaceful way of life that offers break and leisure (Irshad 2010). According Okech, Haghiri and George (2012, 36) "tourism, to be described as rural, should mirror the characteristics that signify a rural area including small settlements, low population densities, agrarian based economies and traditional societies".

As well as tourism impacts in the context of simultaneous consumption and preservation could be positive and negative, commodification and authenticity in rural tourism are paired and contradictory concept. The commodification of rural space is an inevitable aspect of rural consumption (Zhou 2014). Despite the commodification of rural area and 
ToSEE - Tourism in Southern and Eastern Europe, Vol. 6, pp. 559-572, 2021.

I. Pavlić, A. Portolan, B. Puh: IMAGE FORMATION IN RURAL TOURISM DESTINATION

potential negative impacts, positive impacts of tourism development in those areas are much higher considering revitalization of local culture, diversification, and contribution to the well-being of the rural community, increasing the re-population in rural areas and decreasing mass tourism in nearest urban destinations. Rural tourism also reduces the exodus of population from these regions, creates opportunities for new employment (Leković et al. 2020) and is as effective catalyst of revitalization ( $\mathrm{Su}$ et al. 2019). "Its advantages are that it is based on local; initiatives, local management, has local spin-offs, is rooted in local scenery and it taps into local culture" (Okech, Haghiri and George 2012, 38). Rural tourism development also helps small farms that are unable to compete with the settings imposed by the globalization of markets (Ionela, Constantin and Dogaru 2015) and reduces people exposure against economic fluctuations by creating job opportunities and rising incomes (Sharpley 2002; Lo, Sogan and Mohamed 2013; Kheiri and Nasihatkon 2016). Sharpley (2002, 234-235) summarized possible solutions to many of the problems facing rural areas that rural tourism offers:

- "Economic growth, diversification and stabilization through employment creation in new (tourism related) and existing business, trades and crafts; the creation of new markets for agricultural products.

- Socio-cultural development, including the re-population of rural areas; the maintenance and improvement of public services; the revitalization of local crafts, customs and cultural identities; increased opportunities for social contact and exchange.

- Protection and improvement of both natural and built environment and infrastructure".

Tourism destination becomes a rural when it (Ashley and Maxwell 2001, 397):

- "is outside urban centers and covers spaces where human settlement and infrastructure occupy only small patches of the landscape, most of which is dominated by fields and pastures, woods and forest, water, mountain and desert,

- consists of places where most people spend most of their working time on farms,

- has an abundance of cheap land,

- has high transaction costs, associated with long distance and poor infrastructure,

- has geographical conditions that increase political transaction costs and magnify the possibility of elite capture or urban bias, and

- uses the natural, cultural, heritage and accommodation resources available and services belonging to the rural environment".

Many rural areas have the adequate possibility to transform into the cultural and naturebased tourism destinations through making full use of local traditions and nature resources (Chi and Han 2021).

Bearing in mind everything above mentioned toward importance of rural tourism, rural tourism destination has a great potential and could be a strong motivator for sustainable tourism development, and as such should be researched and analyzed. As tourism offer in rural tourism destination encourages differentiation in compering to other rural destination, a good level of recognition should be primary element of that divergence. Such recognition can be realized by developing rural tourism destination image. 
ToSEE - Tourism in Southern and Eastern Europe, Vol. 6, pp. 559-572, 2021.

I. Pavlić, A. Portolan, B. Puh: IMAGE FORMATION IN RURAL TOURISM DESTINATION

\subsection{Rural tourism destination image}

The topic of image of tourism destination has been the issue that received a lot of attention in academic literature resulting in a important role to a better understanding of tourist behavior (Beerli and Martín 2004). It all begun back in the late 1950es when Boulding and Martineau have proposed that tourists behavior is connected to perceived image more than objective reality (Baloglu and McCleary 1999; Wang and Hsu 2010). In this paper tourism destination will be discussed as multidimensional concept structured of rational (cognitive image) and emotional (affective image) interpretations (Beerli and Martín 2004) despite the most used conceptualization developed by Gartner (1994). The cognitive image is based on the beliefs or knowledge that a consumer has towards the resources or attributes of tourism destination (Pike and Ryan, 2004) which are attracting consumer to choose some a destination (Beerli and Martín 2004). Affective image based on consumer's feelings according tourism destination (Baloglu and Brinberg 1997; Baloglu and McCleary 1999). The reason why third component of Gartner 1994 conceptualization (conative component) has not been analyzed in this paper is because conative component is component of action and in this research tourists' who already were in destination have been interviewed.

Despite the growth of tourism destination image studies, limited researches have been undertaken in the area of rural tourism. Since 2009 only a few papers have discussed the image of rural tourism destination (Kokkali, Koutsouris and Chrysochou 2009; Greaves and Skinner 2010; De Jager 2010; Polo Pena et al. 2012; Zhou 2014; Duan et al. 2020; Leković et al. 2020; López-Sanz et al. 2021). Cognitive component of destination image was focus for Peña et al. (2012), Kokkali Koutsouris and Chrysochou (2009) and Leković et al. (2020) researching, while Greaves and Skinner support the importance of incorporating the affective dimension of experience into marketing strategies of rural tourism destinations. Zhou (2014) has, by analyzing a case study of an online image of rural destination, emphasized the concept of rural idyll with natural phenomena, romanticism, authenticity and nostalgia as core elements.

This paper analyses cognitive and affective components of destination image and their impact on overall image in rural area from the point of view of tourists who already arrived and overnighted in that area.

\subsection{A Conceptual Model}

Considering the researched theory, it can be assumed that affective and cognitive structures are directly connected to the overall image of the rural tourism destination. A conceptual model that includes cognitive and affective evaluation and overall image rural tourism destination is shown in Figure 1. 
ToSEE - Tourism in Southern and Eastern Europe, Vol. 6, pp. 559-572, 2021.

I. Pavlić, A. Portolan, B. Puh: IMAGE FORMATION IN RURAL TOURISM DESTINATION

\section{Figure 1: Conceptual model}

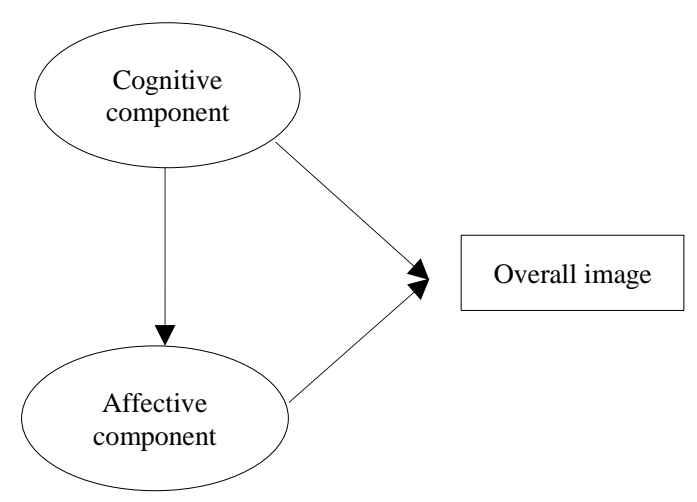

\section{DATA AND METHODOLOGY}

\subsection{Research area}

The researched rural areas near Dubrovnik comprise: Dubrovnik littoral, island Mljet and island Korcula ${ }^{1}$. Those rural areas and are a fragment of Dubrovnik-Neretva County in the Republic of Croatia. Dubrovnik littoral area is situated west of the City of Dubrovnik, only 11 inhabitants per $\mathrm{km} 2$ and accomplishes $1.5 \%$ of tourism in the County. Tourists' arrivals have redoubled in 2017 comparing to 2009 (28893), and in the same period overnights have increased (average year rate 4.4\%). The Island Korcula has 56 inhabitants per $\mathrm{km} 2$. Tourism arrivals have raised in the same period (average year rate $9.3 \%$ ) and also overnights (average year rate $3.7 \%)^{2}$. It achieved $3.8 \%$ of total County arrivals and $6.0 \%$ of County overnight stays in its rural areas (out of settlement of Korcula). Island Mljet is also popular as a tourism destination due to the fact that National park Mljet attracts lot of visitors. With a population of 10.5 inhabitants per $\mathrm{km} 2$ it is less populated area. In the analysed period the number of tourism arrivals has increased (average year growth rate $8 \%$ ). The number of overnights increased. Average year growth rate was $7.5 \%$. Island Mljet achived $1.6 \%$ of total County arrivals and $1.7 \%$ of overnight (Croatia Bureau of Statistics 2017).

\subsection{Sampling, questionnaire design and analytical procedure}

Primary research was conducted with accessible deliberate sample of tourists (600) visited rural areas near Dubrovnik, Croatia, from June 2017 till January 2018. Of the

\footnotetext{
${ }^{1}$ This research and area are determined by the project "Rural educational, cultural and ethnographic tourist attraction" organized by Ministry of regional development and EU funds related to operative programme "Competition and Cohesion 2014 - 2020".

2 Čara, Pupnat and Račišće haven't been included in the total number of arrivals and overnights in rural areas since they were considered as a part of town of Korčula (in 2009.).
} 
ToSEE - Tourism in Southern and Eastern Europe, Vol. 6, pp. 559-572, 2021.

I. Pavlić, A. Portolan, B. Puh: IMAGE FORMATION IN RURAL TOURISM DESTINATION

whole sample, 534 questionnaires were fulfilled correctly. The profile of the sample is shown in Table 1.

In order to collect data a highly structured questionnaire has been used. Questions are based on the literature review. Firstly, questionnaire included questions related to the tourists' socio-demographic characteristics and questions about their travelling, length of stay characteristics, type of accommodation and source of information. Furthermore, questionnaire included cognitive image components that are based on the perceptible features and also on affective components of the image. This part includes 29 statements which contained cognitive attribute ( 24 items and affective attributes ( 5 items) measured on the five-point Likert scale ( $1=$ totally unsatisfied; $5=$ completely satisfied). (Baloglu and McCleary 1999; Pike and Ryan 2004). Fifth part was dedicated on the overall image and included evaluation of overall image of rural destination from one to five (extremely negative to extremely positive. Considering researched literature, it is supposed that cognitive and affective components have influence on the rural tourism destination overall image. This has been tested on the rural tourism destination image, and following hypotheses guided this research:

- Cognitive image is significantly positively related to affective image of rural tourism destination;

- Cognitive image is significantly positively related to overall image of rural tourism destination;

- Affective image is significantly positively related to overall image of rural tourism destination.

The research applied following methods: exploratory factor analysis (EFA) - principal components analysis (PCA) method with Promax rotation was used to define the sub dimensions of cognitive and affective image. The underlying factors derived from EFA were described as correlations among sets of interrelated variables. Confirmatory factor analysis (CFA) has been used to check the measurement cognitive and affective image structure. It has been conducted to determine the reliability and validity by composite reliability (CR which must be higher than 0.70 ). Finally, to achieve the main aim of this paper also structural equation modelling (SEM) was used. Furthermore, the evaluation of the goodness-of-fit guides and the testing hypothesis was applied. All statistical methods were processed applying statistical package SPSS 25.0 and AMOS.

\section{RESULTS AND DISCUSSION}

Regarding the age groups, one quarter of respondents are aged from 36 to 45 years and one fifth are between 46 and 55 years. Only $7.7 \%$ of respondents are aged 66 and older and more than one third are young respondents (38\%). In regards to gender structure, the results indicate almost equal structure. The education structure showed that almost $85 \%$ have higher education. More than $50 \%$ of respondents have personal income between 1501 and 3000 euros and one fifth has between 3001 and above while one quarter has less than 1500 euros. Regarding region of origin, $90 \%$ of respondents come from Europe, mostly from Central and Western part, $4.9 \%$ from Australia and Oceania and $3.0 \%$ from Americas. Only $1.5 \%$ from Asia $0.4 \%$ comes from Australia and Oceania. 
ToSEE - Tourism in Southern and Eastern Europe, Vol. 6, pp. 559-572, 2021.

I. Pavlić, A. Portolan, B. Puh: IMAGE FORMATION IN RURAL TOURISM DESTINATION

Table 1: Respondents' profile

\begin{tabular}{|c|c|c|}
\hline \multirow{2}{*}{ Demographic characteristics } & \multicolumn{2}{|c|}{ Tourists } \\
\hline & Frequency & Percentage \\
\hline \multicolumn{3}{|l|}{ Age } \\
\hline $18-25$ & 99 & 18,9 \\
\hline $26-35$ & 102 & 19,1 \\
\hline $36-45$ & 133 & 24,9 \\
\hline $46-55$ & 110 & 20,6 \\
\hline $56-65$ & 49 & 9,2 \\
\hline $66-$ & 41 & 7,7 \\
\hline \multicolumn{3}{|l|}{ Gender } \\
\hline Male & 274 & 51,3 \\
\hline Female & 260 & 48,7 \\
\hline \multicolumn{3}{|l|}{ Education } \\
\hline Primary School & 3 & 0,6 \\
\hline Secondary school & 82 & 15,4 \\
\hline Undergraduate & 190 & 35,6 \\
\hline Graduate & 194 & 36,3 \\
\hline Postgraduate & 65 & 12,2 \\
\hline \multicolumn{3}{|c|}{ Personal monthly income (in EUR) } \\
\hline-500 & 48 & 9,0 \\
\hline $501-1.500$ & 90 & 16,9 \\
\hline $1.501-2.000$ & 108 & 20,2 \\
\hline $2.001-2.500$ & 87 & 16,3 \\
\hline $2.501-3.000$ & 92 & 17,2 \\
\hline $3.001-3.500$ & 45 & 8,4 \\
\hline $3.501-4 . .000$ & 32 & 6,0 \\
\hline $4.001-$ & 32 & 6,0 \\
\hline \multicolumn{3}{|l|}{ Region of origin } \\
\hline Northern Europe & 31 & 5,8 \\
\hline Western Europe & 140 & 26,2 \\
\hline Central Europe & 172 & 32,2 \\
\hline Southern Europe & 96 & 18,0 \\
\hline Southeast Europe & 32 & 6,0 \\
\hline Eastern Europe & 13 & 2,4 \\
\hline North America & 14 & 2,6 \\
\hline Australia and Oceania & 26 & 4,9 \\
\hline Asia & 8 & 1,5 \\
\hline South America & 2 & 0,4 \\
\hline
\end{tabular}

Source: Authors' research

In order to define the sub dimensions of cognitive and affective image exploratory factor analysis (EFA) by principal components analysis (PCA) method with Promax rotation. To test scale reliability and validity, Cronbach's alpha $(\boldsymbol{\alpha})$, average variance extracted (AVE) and composite reliability (CR) and convergent validity (factor loadings) were used. Table 2 represents results. Factor loadings those are greater than 0.6 are recommended for analysis (Hair et al. 2011). The factor loadings values were above 0.6 ranging from 0.675 (peaceful atmosphere) to 0.883 (services in accommodation). Cronbach's alpha coefficient of all factors were greater than 0.7 (above 0.7 are acceptable Nunnally and Bernstein 1994). According Bagozzi and Yi (1988), AVE values above 
ToSEE - Tourism in Southern and Eastern Europe, Vol. 6, pp. 559-572, 2021.

I. Pavlić, A. Portolan, B. Puh: IMAGE FORMATION IN RURAL TOURISM DESTINATION

0.5 are considered to be adequate. All AVE results were above 0.5 , ranging from 0.575 (entertainment) to 0.799 (culture). Composite reliability is required to be higher than 0.7 (Kline 2010).

Table 2: Factor loadings, variance explained, Cronbach's alpha, AVE and composite reliability

\begin{tabular}{|c|c|c|c|c|c|}
\hline Variables & Factors & $\begin{array}{c}\text { Variance } \\
\text { explained (\%) }\end{array}$ & $\alpha$ & AVE & $\mathrm{CR}$ \\
\hline \multicolumn{6}{|l|}{ COGNITIVE EVALUATION } \\
\hline Environment (COG1) & & 25,657 & 0,777 & 0,659 & 0,852 \\
\hline Scenic and natural beauty & 0,802 & & & & \\
\hline Environmental preservation & 0,878 & & & & \\
\hline Cleanliness & 0,751 & & & & \\
\hline Accessibility/Value (COG2) & & 13,539 & 0,782 & 0,643 & 0,843 \\
\hline Accessibility of the destination & 0,845 & & & & \\
\hline Good signage for visitors & 0,825 & & & & \\
\hline Good value for money & 0,732 & & & & \\
\hline Entertainment (COG3) & & 8,812 & 0,826 & 0,575 & 0,870 \\
\hline Nightlife and entertainment & 0,733 & & & & \\
\hline Recreational facilities & 0,742 & & & & \\
\hline Entertainment prices & 0,701 & & & & \\
\hline Authentic experience & 0,853 & & & & \\
\hline Local manifestation & 0,754 & & & & \\
\hline Culture (COG4) & & 8,824 & 0,783 & 0,799 & 0,888 \\
\hline Experience with local culture & 0,861 & & & & \\
\hline Cultural offer & 0,926 & & & & \\
\hline Accommodation (COG5) & & 7,166 & 0,839 & 0,688 & 0,868 \\
\hline The quality of accommodation & 0,804 & & & & \\
\hline Services in accommodation & 0,883 & & & & \\
\hline Prices of accommodation & 0,799 & & & & \\
\hline AFFECTIVE EVALUATION (AFF) & & 5,913 & 0,766 & 0,571 & 0,841 \\
\hline Friendliness of local people & 0,727 & & & & \\
\hline Relaxing atmosphere & 0,823 & & & & \\
\hline Pleasant atmosphere & 0,790 & & & & \\
\hline
\end{tabular}

Source: Authors' research

To further validate the properties of the scale items CFA has been conducted. The chisquare was significant at 0.000 level. GFI was 0.951 . The GFI ranges between zero and one with higher values demonstrating better fit (Marsh and Grayson 1995), AGFI is 0.912 - a rule is that index above 0.90 is good fit relative to the baseline model, while values above 0.85 may be considered as a suitable fit (Schermelleh-Engel, Moosbrugger and Müller 2003). CFI was 0.971. The CFI ranges from zero to one with higher values pointing out better fit. This index shows that values above 0.97 is indicative of good fit while values greater than 0.95 may be took as an acceptable fit ( $\mathrm{Hu}$ and Bentler 1995). RMSEA was found to be 0.066. According to Browne and Cudeck (1993), RMSEA values bellow 0.05 can be taken as a good fit, values between 0.05 and 0.08 as an acceptable fit which means that this model is adequate. Figure 2 presents results from CFA. 
ToSEE - Tourism in Southern and Eastern Europe, Vol. 6, pp. 559-572, 2021.

Figure 2: Results of CFA

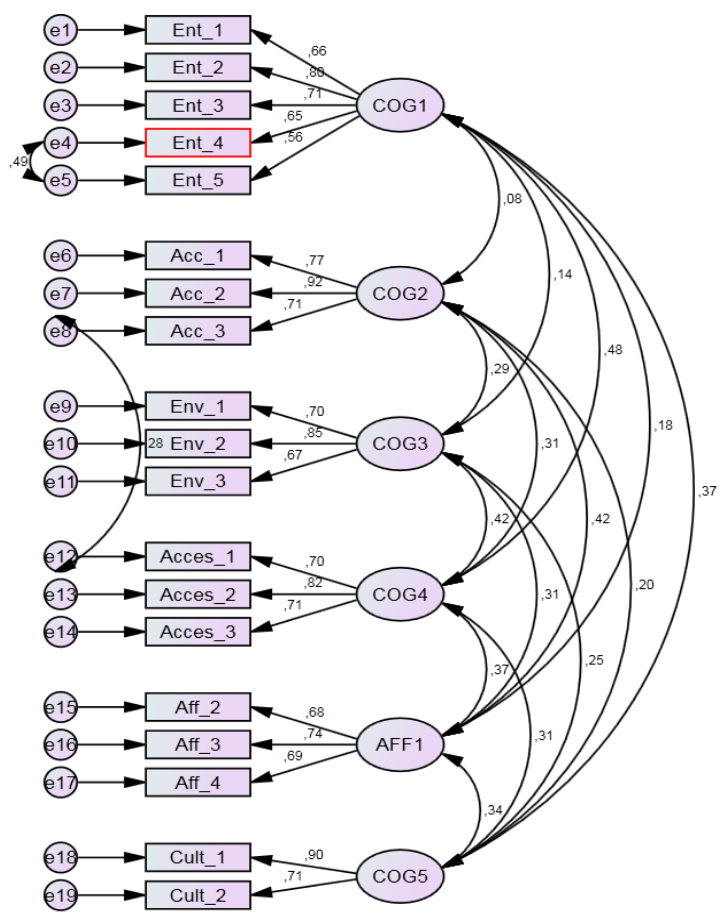

Source: Authors' research

P- values of all observed variables are found to be significant. The correlations between factors are all below 0.5 which means that the model is good.

The next step was to apply SEM to determine the impact of different cognitive and affective factor on overall image of rural destination. Analysis shows that all goodness of fit indicators were significant and positive (GFI was 0.964, AGFI 0.922, CFI 0.933 and RMSEA 0.031).

Table 3: Regression weight estimates between factors of the path model

\begin{tabular}{|c|c|c|c|c|c|c|}
\hline & & & Estimate & S.E. & C.R. & $\mathrm{P}$ \\
\hline COG1 & $\langle--\rangle$ & AFF1 & .238 & .014 & 10.186 & $* * *$ \\
\hline COG2 & $\langle--\rangle$ & AFF1 & .165 & .013 & 4.980 & $* * *$ \\
\hline COG3 & $\langle--\rangle$ & AFF1 & .221 & .010 & 8.253 & $* * *$ \\
\hline COG4 & $\langle-->$ & AFF1 & .232 & .014 & 9.447 & $* * *$ \\
\hline COG5 & $\langle--\rangle$ & AFF1 & .225 & .012 & 8.739 & $* * *$ \\
\hline
\end{tabular}

$* * * \mathrm{p}<0.001$

Source: Authors' research

The results from table 3 indicate that cognitive factors have significant and positive influence on affective one which confirms the first hypothesis. 
ToSEE - Tourism in Southern and Eastern Europe, Vol. 6, pp. 559-572, 2021.

I. Pavlić, A. Portolan, B. Puh: IMAGE FORMATION IN RURAL TOURISM DESTINATION

Table 4: Regression weight estimates of the path model

\begin{tabular}{lllrrrr}
\hline & & & Estimate & \multicolumn{1}{l}{ S.E. } & C.R. & P \\
\hline IMAGE & $<---$ & COG1 & .197 & .046 & 4.511 & $* *$ \\
IMAGE & $<--$ & COG2 & .108 & .044 & 2.336 & $* * *$ \\
IMAGE & $<--$ & COG3 & .102 & .048 & 2.122 & $*$ \\
IMAGE & $<--$ & COG4 & .107 & .051 & 2.090 & $*$ \\
IMAGE & $<---$ & COG5 & .041 & .055 & .734 & NS \\
IMAGE & $<---$ & AFF1 & .477 & .072 & 6.595 & $* * *$ \\
\hline
\end{tabular}

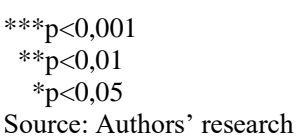

Table 4 shows the results of regression weight of the path model. As seen form table affective factor has the biggest influence on overall image following by first and second cognitive factor while fifth cognitive factor is not significant. Third and fourth cognitive factor are also significant and have positive impact on overall image.

In forming the image of rural tourism destination friendliness of local people and relaxing and pleasant atmosphere have the biggest positive impact on overall image. It seems that in rural surroundings the atmosphere is dominant in comparison with cognitive elements. This can be explained with the fact that cognitive elements of various destinations are quite similar and that affective elements are those on which differentiation strategy can be based.

Regarding cognitive elements, the biggest influence can be found in scenic and natural beauty, environmental preservation and cleanliness of destination. These elements are closely related to affective components because of its direct influence on creating rural destination atmosphere. In the next group of cognitive elements value for money that destination provides, good signage for visitors and accessibility of destination are found to have impact on image creation. The least influence has third cognitive factor which includes nightlife and entertainment, recreational facilities, entertainment prices, authentic experience and local manifestation.

The structural model (Figure 3) shows standardizes coefficients and statistical significance of researched parameters. It also provides support for all set hypothesis. Since four of five cognitive factors have positive and statistically significant influence on overall image, second hypothesis has been confirmed. Third hypothesis stating that affective image is significantly positively related to overall image of rural tourism destination has also been confirmed since affective images have the biggest influence on overall image of rural destination comparing with López-Sanz et al. (2021) who confirmed that cognitive image dimension has the most important positive influence on image. 
ToSEE - Tourism in Southern and Eastern Europe, Vol. 6, pp. 559-572, 2021.

\section{Figure 3: The structural model}

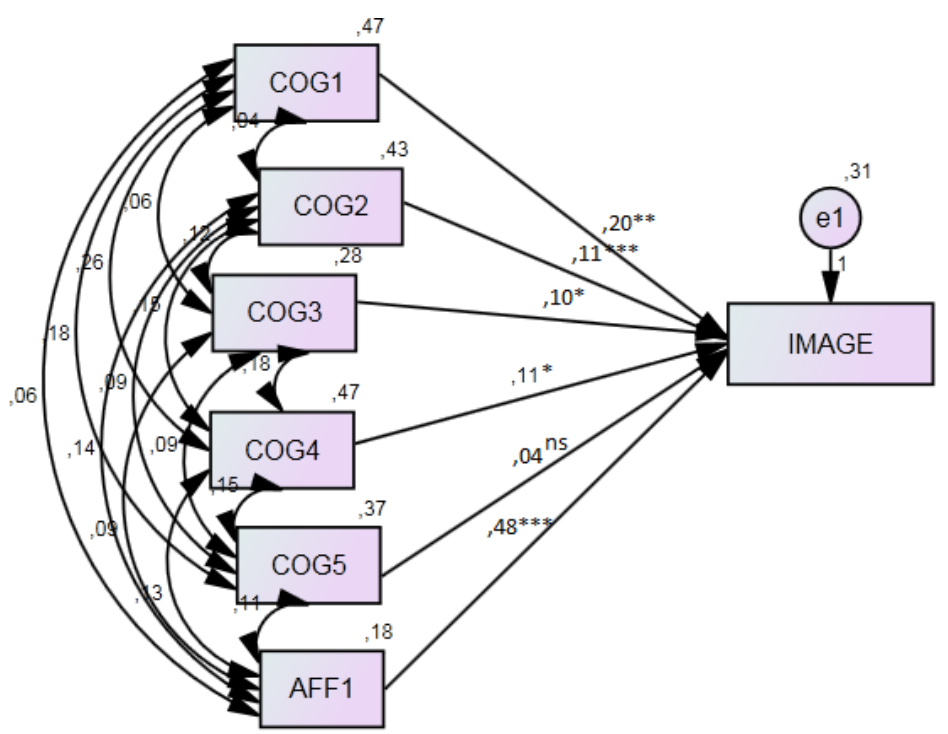

$$
\begin{aligned}
& * * * \mathrm{p}<0,001 \\
& * * \mathrm{p}<0,01 \\
& * \mathrm{p}<0,05 \\
& \text { Source: Authors' research }
\end{aligned}
$$

\section{CONCLUSION}

Many rural areas are nowadays facing problems with agricultural decline, depopulation and development delay and tourism can be seen as one of the most important determinant of that trend change. The potential of rural tourism can be seen in year-round business which can help in reducing the seasonality of coastal destinations and unburden the overloaded urban spaces. It can provide much needed return to nature, stress relief, rest and relaxation especially in COVID 19 pandemic surroundings.

Image of a rural destination is one of the areas of research in which there is still space from in depth progress. Defining cognitive and affective elements of image can be crucial for rural destination development, its positioning on competitive tourism market and further economic development of the area.

Results of this research indicate that cognitive image is positively related to affective and overall image and that affective image is positively related to overall image meaning that tourists form image of rural destination based on physical (tangible) but also on psychological (intangible) elements of destination. The fact that affective image has the higher impact on overall image highlights the importance of feelings and atmosphere in destination on positive perception of tourists. This can be seen as an important factor for destination branding since all destinations have similar points of parity (tourist 
ToSEE - Tourism in Southern and Eastern Europe, Vol. 6, pp. 559-572, 2021.

I. Pavlić, A. Portolan, B. Puh: IMAGE FORMATION IN RURAL TOURISM DESTINATION

infrastructure and suprastructure) but atmosphere is something which is unique and hard to copy making it a good base for destination differentiation.

This paper has several limitations. Since convenience purposive sample was used the results have to be treated with caution and cannot be generalized to the whole population. The time of conducting research was from June to January which means that results could have been different if the research had been taken in some other period. Cognitive elements of rural destination are adjusted for the destination in question meaning that some other cognitive elements of destination could have been found important in different rural destination.

Future research should apply one of the probability sampling techniques in order to be able to generalize the results. It is suggested to conduct research in different period of year (high, low and out of season) to see the possible differences in destination image perception. Also, future research could try to include additional cognitive elements of destination to make a base for better differentiating and positioning of rural destination and socio-demographic control variables to explore possible differences between different segments of tourists.

\section{REFERENCES}

Alberta, Department of Agriculture and Rural Development. Rural Development Division and Irshad, H (2010), Rural tourism-an overview. Edmonton, Canada: Government of Alberta.

Ashley, C. and Maxwell, S. (2001), "Rethinking rural development", Development Policy Review, Vol. 19, No. 4, pp. 395-425. https://doi.org/10.1111/1467-7679.00141

Bagozzi, R.P. and Yi, Y. (1988), "On the Evaluation for Structural Equation Models”, Journal of the Academy of Marketing Science, Vol. 16, pp. 74-94. https://doi.org/10.1007/BF02723327

Beerli, A. and Martin, J.D. (2004), "Factors influencing destination image", Annals of Tourism Research, Vol. 31, No. 3, pp. 657-681. https://doi.org/10.1016/j.annals.2004.01.010

Baloglu, S. and Brinberg, D. (1997), "Affective images of tourism destinations", Journal of Travel Research, Vol. 35, No. 4, 11-15. https://doi.org/10.1177/004728759703500402

Baloglu, S. and McCleary, K.W. (1999), "A model of destination image formation", Annals of Tourism Research, Vol. 26, No. 4, pp. 868-897. https://doi.org/10.1016/S0160-7383(99)00030-4

Browne, M.W. and Cudeck, R. (1993), “Alternative ways of assessing model fit", in Bollen, K.A. and Long J.S. (Eds.), Testing structural equation models, Sage Newbury Park, CA, pp. 136-162.

Chi, X. and Han, H. (2021), "Emerging rural tourism in China's current tourism industry and tourist behaviors: the case of Anji County", Journal of Travel \& Tourism Marketing, Vol. 38, No. 1, 58-74. https://doi.org/10.1080/10548408.2020.1862026

De Jager, A.E. (2010), "How dull is Dullstroom? Exploring the tourism destination image of Dullstroom", Tourism Geographies, Vol. 12, No. 3, pp. 349-370. https://doi.org/10.1080/14616688.2010.495757

Duan, X., Marafa, L.M., Chan, C.S., Xu, H. and Cheung, L.T. (2020), Measuring the Gaps in the Projected Image and Perceived Image of Rural Tourism Destinations in China's Yangtze River Delta. Sustainability, Vol. 12, No. 12, 5121. https://doi.org/10.3390/su12125121

Gartner, W.C. (1994), "Image formation process", Journal of Travel \& Tourism Marketing, Vol. 2, No. 2-3, pp. 191-216. https://doi.org/10.1300/J073v02n02_12

Greaves, N. and Skinner, H. (2010), "The importance of destination image analysis to UK rural tourism", Marketing Intelligence \& Planning, Vol. 28, No. 4, pp. 486-507.

Ionela, G.P., Constantin, B.M. and Dogaru, L.D. (2015), "Advantages and limits for tourism development in rural area (Case Study Ampoi and Mureş Valleys)", Procedia Economics and Finance, Vol. 32, pp. 1050-1059. https://doi.org/10.1016/S2212-5671(15)01567-1

Hair, J.F., Ringle, C.M. and Sarstedt, M. (2011), "PLS-SEM: Indeed a silver bullet", Journal of Marketing Theory and Practice, Vol. 19, No. 2, pp. 139-152. https://doi.org/10.2753/MTP1069-6679190202 
ToSEE - Tourism in Southern and Eastern Europe, Vol. 6, pp. 559-572, 2021.

I. Pavlić, A. Portolan, B. Puh: IMAGE FORMATION IN RURAL TOURISM DESTINATION

Hu, L. and Bentler, P. (1995), "Evaluating model fit", in Hoyle, R.H. (Ed.), Structural equation modeling. Concepts, issues, and applications, Sage, London, pp. 76-99.

Kheiri, J. and Nasihatkon, B. (2016), "The effects of rural tourism on sustainable livelihoods (case study: Lavij rural, Iran)", Modern Applied Science, Vol. 10, No. 10, pp. 10-22. http://dx.doi.org/10.5539/mas.v10n10p10

Kline, R.B. (2010), Principles and Practice of Structural Equation Modeling, The Guilford Press, New York.

Kokkali, P., Koutsouris, A. and Chrysochou, P. (2009), "Cognitive components of rural tourism destination images: The case of Lake Plastiras, Greece", Tourismos, Vol. 4, No. 4, pp. 273-291.

Leković, K., Tomić, S., Marić, D. and Curčić, N.V. (2020), "Cognitive Component of the Image of a Rural Tourism Destination as a Sustainable Development Potential”, Sustainability, Vol. 12, No. 22, 9413. https://doi.org/10.3390/su12229413

Lo, M.C., Songan, P., Mohamad, A.A. and Yeo, A.W. (2013), "Rural tourism and destination image: Community perception in tourism planning", The Macro-Theme Review, Vol. 2, No. 1, pp. $102-118$.

López-Sanz, J.M., Penelas-Leguia, A., Gutierrez-Rodriguez, P. and Cuesta-Valino, P. (2021), Sustainable development and consumer behavior in rural tourism - The importance of image and loyalty for host communities", Sustainability, Vol. 13, 4763. https://doi.org/10.3390/su13094763

Marsh, H.W. and Grayson, D. (1995), "Latent variable models of multitrait-multimethod data", in Hoyle, R. (Ed.), Structural equation modeling: Concepts, issues and applications, Sage Thousand Oaks, CA pp. $177-198$.

Nunnally, J.C. and Bernstein, I.H. (1994), Psychometric theory (3rd ed.), McGraw-Hill, New York, NY.

Okech, R., Haghiri, M. and George, B.P. (2012), "Rural tourism as a sustainable development alternative: An analysis with special reference to Luanda, Kenya", CULTUR-Revista de Cultura e Turismo, Vol. 6, No. 3, pp. 36-54.

Peña, A.I.P., Jamilena, D.M.F. and Molina, M.Á.R. (2012), "Validation of cognitive image dimensions for rural tourist destinations: A contribution to the management of rural tourist destinations", Journal of Vacation Marketing, Vol. 18, No. 4, pp. 261-273. https://doi.org/10.1177/1356766712449351

Pike, S. and Ryan, C. (2004), "Destination positioning analysis through a comparison of cognitive, affective, and conative perceptions", Journal of Travel Research, Vol. 42, No. 4, pp. 333-342. https://doi.org/10.1177/0047287504263029

Ružić, P. (2009), Ruralni turizam, Institut za poljoprivredu i Turizam, Poreč, Pula.

Schermelleh-Engel K., Moosbrugger H., Müller H. (2003), "Evaluating the fit of structural equation models: tests of significance and descriptive goodnessof-fit measures", Methods Psychol. Res. Online, Vol 8, No. 2, pp. 23-74

Sharpley, R. (2002), "Rural tourism and the challenge of tourism diversification: the case of Cyprus", Tourism Management, Vol. 23, No. 3, pp. 233-244. https://doi.org/10.1016/S0261-5177(01)00078-4

Su, M.M., Wall, G., Wang, Y. and Jin, M. (2019), "Livelihood sustainability in a rural tourism destinationHetu Town, Anhui Province, China", Tourism Management, Vol. 71, pp. 272-281. https://doi.org/10.1016/j.tourman.2018. 10.019

Wang, C.Y. and Hsu, M.K. (2010), The relationships of destination image, satisfaction, and behavioral intentions: An integrated model", Journal of Travel \& Tourism Marketing, Vol. 27, No. 8, pp. 829843. https://doi.org/10.1080/10548408.2010.527249

Zhou, L. (2014), “Online rural destination images: Tourism and rurality”, Journal of Destination Marketing \& Management, Vol. 3, No. 4, pp. 227-240. https://doi.org/10.1016/j.jdmm.2014.03.002 
ToSEE - Tourism in Southern and Eastern Europe, Vol. 6, pp. 559-572, 2021.

I. Pavlić, A. Portolan, B. Puh: IMAGE FORMATION IN RURAL TOURISM DESTINATION

\author{
Ivana Pavlić, Full Professor \\ University of Dubrovnik \\ Department of Economics and Business \\ Lapadska obala 7, Dubrovnik, Croatia \\ $+38520445929$ \\ ipavlic@unidu.hr
}

Ana Portolan, Assistant Professor

University of Dubrovnik

Department of Economics and Business

Lapadska obala 7, Dubrovnik, Republic of Croatia

+ 38520445923

ana.portolan@unidu.hr

Barbara Puh, Assistant Professor

University of Dubrovnik

Department of Economics and Business

Lapadska obala 7, Dubrovnik, Republic of Croatia

+ 38520445923

barbara.puh@unidu.hr 